\title{
The effect of dutasteride on the detection of prostate cancer: A set of meta-analyses
}

\author{
Neerav Monga, MSc,; Amyn Sayani, PhD; Daniel A. Rubinger, MBiotech; ${ }^{*}$ Timothy H. Wilson, MS; \\ Zhen $S u, M D, M B A^{*}$
}

*Medical Affairs, GlaxoSmithKline Canada, Mississauga, ON; †GlaxoSmithKline, Research Triangle Park, NC

Cite as: Can Urol Assoc J 2013;7:E161-E167. http://dx.doi.org/10.5489/cuaj.477

\section{Abstract}

Background: Dutasteride has been shown to significantly improve symptoms of benign prostatic hyperplasia $(\mathrm{BPH})$ and reduce clinical progression. Recent data from studies evaluating 5-alpha reductase inhibitors (5-ARIs) for the prevention of prostate cancer, however, suggest $5 \mathrm{ARI}$, including dutasteride, may be associated with increased incidence of Gleason 8-10 prostate tumours. This metaanalysis was undertaken to quantify the effect of dutasteride on detection of prostate cancer and high-grade prostate cancer.

Methods: Our meta-analysis includes data from GlaxoSmithKlinesponsored phase III randomized clinical trials (with a study duration of $\geq 2$ years) evaluating the effect of dutasteride, alone or in combination with tamsulosin, to treat $\mathrm{BPH}$ or to reduce the risk of prostate cancer. The incidence of prostate cancer, including Gleason 7-10 and Gleason 8-10, for patients taking either dutasteride, dutasteride plus tamsulosin, tamsulosin alone, or placebo, were evaluated using the Mantel-Haenszel Risk Ratio (MHRR) method of conducting meta-analyses.

Results: The meta-analysis demonstrated that in a population with symptomatic BPH and/or at increased risk of prostate cancer, a statistically significant lower number of detectable prostate cancers was found in men taking dutasteride compared to control groups (MHRR: $0.66,95 \% \mathrm{Cl} 0.52-0.85)$. In our analysis, there was no increased risk for Gleason 7-10 (MHRR: 0.83, 95\% CI 0.56-1.21) or Gleason 8-10 prostate cancers (MHRR: 0.99, 95\% Cl 0.392.53 ) in men taking dutasteride over control groups. There were several limitations that need to be considered when interpreting these results.

Conclusion: These data provide support for the continued use of dutasteride in the treatment of symptomatic BPH patients.

\section{Introduction}

Prostate conditions, such as benign prostatic hyperplasia $(\mathrm{BPH})$, remain a significant concern in men, especially for those over age 50 . It is estimated that $40 \%$ of men over 50 and $90 \%$ over 80 have $\mathrm{BPH} .{ }^{1,2}$ In Canada, the number of men 50 years and over is projected to grow by over $37 \%$ to 6.5 million by 2018 , and the number of men with moder- ate-severe lower urinary tract symptoms (LUTS) is expected to increase by $41 \%$ to 2.6 million. $^{3} \mathrm{BPH}$ has a significant economic burden on society with direct annual costs of $\$ 1.1$ billion in the year 2000 in the United States alone, exclusive of outpatient medication. ${ }^{4}$

Medical treatments for $\mathrm{BPH}$ include 5-alpha reductase inhibitors (5-ARIs), which block the conversion of testosterone to dihydrotestosterone (DHT) via 5-alpha reductase (5-AR). ${ }^{5}$ Dutasteride inhibits both isoforms of 5-AR and reduces serum DHT by more than $90 \%$, subsequently reducing prostate volume and improving $\mathrm{BPH}$ symptoms. ${ }^{5,6}$ Levels of both isoforms of 5-AR are slightly increased in $\mathrm{BPH}$ compared to the normal prostate, while mainly type 1 5-AR levels are increased in prostate cancer tissue. ${ }^{7}$ Theoretically, suppression of prostatic DHT may also affect the development and progression of prostate neoplasia.

Prostate cancer incidence was reported in several Phase III studies that evaluated the efficacy of dutasteride to treat symptomatic BPH. In a pooled analysis of three Phase III BPH monotherapy studies (ARIA3001, ARIA3002, ARIB3003), the incidence of detectable prostate cancer reported as an adverse event, determined by for-cause biopsies, was almost $50 \%$ less in the dutasteride group compared to the placebo group at 27 months (1.2 and $2.5 \%, p=0.002) .{ }^{8}$ In a posthoc analysis of the Combination of Avodart and Tamsulosin (CombAT) study in BPH patients, dutasteride, alone or in combination with tamsulosin, showed a relative reduction of $40 \%$ in the risk of detectable prostate cancers compared to tamsulosin monotherapy, as well as a $40 \%$ reduction in biopsies, over the 4-year study duration. ${ }^{9}$ There were numerically fewer Gleason score 7-10 and Gleason score 8-10 tumours in the dutasteride groups combined, compared with the tamsulosin group, and a similar reduction of $40 \%$ was observed for low- and high-grade Gleason score cancers as for all tumours. ${ }^{9}$

5-ARIs have also been examined in prostate cancer chemoprevention. The Prostate Cancer Prevention Trial (PCPT) study showed a reduction in the incidence of forcause prostate cancer of $24.8 \%$ in normal men treated with finasteride after 7 years. ${ }^{10}$ The REduction by DUtasteride of 
prostate Cancer Events (REDUCE) trial demonstrated that dutasteride significantly reduced the incidence of protocolmandated biopsy-detectable prostate cancer by $22.8 \%$ compared to placebo after 4 years in a biopsy negative atrisk population. ${ }^{11}$ While these studies showed a decrease in incidence of overall prostate cancers in men administered dutasteride or finasteride over placebo, there was an increased incidence of Gleason grade 8-10 in patients taking dutasteride, and an increased incidence of Gleason 7-10 in patients taking finasteride. ${ }^{10,11}$ Dutasteride treatment in REDUCE yielded an absolute increase of $0.3 \%$ in the incidence of grade 8-10 prostate cancers compared to placebo, using the classical Gleason scoring system, ${ }^{8}$ and $0.5 \%$ using the modified Gleason scores. ${ }^{12}$ In PCPT, a statistically significant higher incidence of grade 8-10 cancers was seen in the finasteride group over the placebo overall $(0.96 \%$ vs. $0.56 \%$; relative risk $1.70[95 \% \mathrm{Cl} 1.22-2.39]) .{ }^{10}$

Taken together, these results suggest that patients taking 5-ARIs may be at an increased risk for developing highgrade prostate cancer, a finding that has led to labelling changes in Canada, Europe and the U.S. This has subsequently increased concern among patients and physicians, even though these labelling changes also indicate a favourable benefit:risk profile for 5 -ARIs in the treatment of $\mathrm{BPH}$.

In the present study, we undertook a meta-analysis of all GlaxoSmithKline (GSK)-sponsored Phase III studies in which dutasteride was evaluated for the treatment of $\mathrm{BPH}$ or for risk reduction of prostate cancer prior to 2012, in an effort to quantify the effect of dutasteride on the detection of prostate cancer and high-grade prostate cancer.

\section{Methods}

\section{Selection of studies}

All GSK-sponsored Phase III randomized, double-blind, controlled trials ( $\geq 2$ years' duration) with dutasteride compared to an active comparator/placebo in the treatment of $\mathrm{BPH}$ or risk reduction of prostate cancer were eligible for inclusion. We excluded prior studies that did not report prostate cancer. The occurrence of prostate cancer in the following studies was used for the analysis:

- BPH monotherapy studies (ARIA3001, ARIA3002, ARIB3003): 2-year studies, comprising 4325 men, to evaluate efficacy and safety of dutasteride $0.5 \mathrm{mg}$ once daily to treat symptomatic men. Biopsies were conducted "for-cause" only, based on the investigator's judgment, and Gleason scores were not collected prospectively. The intent-to-treat population was used in the analyses.

- CombAT: A 4-year study in 4844 men, in which dutasteride in combination with tamsulosin was com- pared to dutasteride or tamsulosin monotherapy, for improving $\mathrm{BPH}$ symptoms, and to reduce the risk of acute urinary retention (AUR) and BPH-surgery. Biopsies were conducted for-cause only, based on the investigator's judgment. The intent-to-treat population was used for the analyses.

- REDUCE: A 4-year study in 8231 men, in which dutasteride at a dose of $0.5 \mathrm{mg}$ daily was compared with placebo to reduce the risk of prostate cancer in men who were at increased risk of the disease. Subjects underwent a 10-core transrectal ultrasound-guided biopsy at 2 and 4 years. Biopsies were also conducted at any time during the study at the investigator's discretion if clinically indicated. The safety population was used for the analyses.

Classical Gleason scores were used to report biopsy results in CombAT and REDUCE, but not prospectively collected in BPH monotherapy studies. These studies represent an exposure to dutasteride of about 25900 patient-years. Data from the REDEEM study were not included as the study was not yet complete at the time of the meta-analysis. ${ }^{13}$

\section{Statistical methods}

The standard Mantel-Haenszel Risk Ratio (MHRR) method of conducting meta-analyses was used in this study to estimate the pooled risk ratio. Between-study heterogeneity across the eligible comparisons was quantitatively assessed using the $\chi^{2}$-based $Q$ statistical test and $\mathrm{I}^{2}$ score. ${ }^{14,15}$ Heterogeneity was considered statistically significant when the $\mathrm{Q}$ statistical test was $p<0.05$ (two-sided). When low heterogeneity was found, the fixed effects model was used for the analysis, while for moderate-high heterogeneity, the random effects model was used. The Comprehensive Meta-Analysis software version 2.20.050 (November 10, 2009) ${ }^{16}$ was used to conduct this meta-analysis.

\section{Results}

We tallied study characteristics for the randomized controlled trials used in the meta-analysis (Table 1). While the patient population differs between the $\mathrm{BPH}$ and prostate cancer risk reduction studies, the meta-analysis allows for a broader look at the effect of dutasteride on the detection of prostate cancers in patients who have a wide range of prostate-specific antigen (PSA) values, prostate volume and symptom scores, as defined by the International Prostate Symptom Score (IPSS).

\section{Any prostate cancers}

Any prostate cancers were defined as a total of all types of prostate cancer detected in patients, regardless of Gleason 


\begin{tabular}{|c|c|c|c|c|c|c|c|}
\hline $\begin{array}{l}\text { Study; year of } \\
\text { publication }\end{array}$ & $\begin{array}{c}\text { No. } \\
\text { subjects }\end{array}$ & $\begin{array}{c}\text { Primary } \\
\text { endpoint }\end{array}$ & Intervention & $\begin{array}{c}\text { Treatment } \\
\text { duration }\end{array}$ & $\begin{array}{c}\text { Inclusion } \\
\text { criteria }\end{array}$ & Incidence of prostate cancer & Notes \\
\hline $\begin{array}{l}\text { ARIA series } \\
\text { (ARIA3001, } \\
\text { ARIA3002, } \\
\text { ARIB3003; } \\
\text { dutasteride } \\
\text { BPH } \\
\text { monotherapy); } \\
2004\end{array}$ & 4325 & $\begin{array}{l}\text { BPH } \\
\text { symptomatic } \\
\text { relief; prostate } \\
\text { cancer } \\
\text { evaluated for- } \\
\text { cause as an } \\
\text { adverse effect }\end{array}$ & $\begin{array}{l}\text { Dutasteride, } 0.5 \\
\text { mg daily ( } n=2167) ; \\
\text { placebo daily } \\
(n=2158)\end{array}$ & 2 years & $\begin{array}{l}\text { PSA } 1.5-10 \\
\text { IPSS } \geq 12 \\
P V \geq 30 \mathrm{cc}\end{array}$ & $\begin{array}{c}\text { Cumulative incidence of } \\
\text { prostate cancer at } 24 \text { mos for } \\
\text { dutasteride vs. placebo: } 1.1 \% \\
\text { vs. } 1.9 \%, p=0.025 \text { at } 24 \text { mos; } \\
1.2 \% \text { vs. } 2.5 \%, p=0.002 \text { at } 27 \\
\text { mos; } 51 \% \text { risk reduction at } \\
27 \text { mos }\end{array}$ & $\begin{array}{c}\text { Pooled } \\
\text { analysis of } 3 \\
\text { monotherapy } \\
\text { trials; } \\
\text { for-cause } \\
\text { biopsies }\end{array}$ \\
\hline REDUCE; 2010 & 8231 & $\begin{array}{l}\text { Prostate cancer } \\
\text { detected on } \\
\text { biopsy after } 2 \\
\text { or } 4 \text { years of } \\
\text { treatment }\end{array}$ & $\begin{array}{l}\text { Dutasteride, } 0.5 \\
\text { mg daily }(n=4105) \\
\text { placebo daily } \\
(n=4126)\end{array}$ & 4 years & $\begin{array}{l}\text { PSA } 2.5-10 \\
\text { IPSS <25 } \\
\text { PV } \leq 80 \mathrm{cc}\end{array}$ & $\begin{array}{c}\text { Absolute risk reduction of } \\
5.1 \% \text { in dutasteride group } \\
\text { over } 4 \text { years; Relative risk } \\
\text { reduction: } 22.8 \%(95 \% \mathrm{Cl} \text { : } \\
\quad 15.2-29.8, p<0.001)\end{array}$ & $\begin{array}{l}\text { Protocol- } \\
\text { mandated } \\
\text { biopsies }\end{array}$ \\
\hline CombAT; 2011 & 4844 & $\begin{array}{l}\text { Time to first } \\
\text { AUR or BPH- } \\
\text { related surgery } \\
\text { in symptomatic } \\
\text { BPH patients; } \\
\text { Prostate cancer } \\
\text { evaluated for- } \\
\text { cause as an } \\
\text { adverse effect }\end{array}$ & $\begin{array}{l}\text { Dutasteride, } 0.5 \\
\text { mg daily ( } n=1623) \\
\text { Tamsulosin } 0.4 \\
\text { mg daily ( } n=1611) \\
\text { combination } \\
\text { (dutasteride } 0.5 \\
\text { mg + tamsulosin } \\
0.4 \text { mg) }(n=1610) \\
\text { daily }\end{array}$ & 4 years & $\begin{array}{l}\text { PSA } 1.5-10 \\
\text { IPSS } \geq 12 \\
P V \geq 30 \mathrm{cc}\end{array}$ & $\begin{array}{c}\text { PCa detection of } 2.3 \% \\
\text { combination group; } 2.6 \% \\
\text { in dutasteride group; } \\
\text { and } 3.9 \% \text { in tamsulosin; } \\
\text { relative risk reduction of } \\
40 \% \text { for dutasteride (alone } \\
\text { or in combination with } \\
\text { tamsulosin) vs. tamsulosin } \\
\text { monotherapy (95\% } \\
\text { confidence interval, } 16-57 \% ; \\
p=0.002 \text { ) }\end{array}$ & $\begin{array}{c}\text { For-cause } \\
\text { biopsies }\end{array}$ \\
\hline
\end{tabular}

BPH: benign prostatic hyperplasia; IPSS: International Prostate Symptom Score; AUR: acute urinary retention; Mos: Months; PSA: prostate-specific antigen; PV: prostate volume; CombAT: Combination of Avodart And Tamsulosin trial; REDUCE: REduction by DUtasteride of prostate Cancer Events; Cl: confidence interval.

score or whether a biopsy was mandated by the protocol or at the investigator's judgment. We illustrate the effect of dutasteride $(0.5 \mathrm{mg}$ daily) or dutasteride $(0.5 \mathrm{mg}$ daily) + tamsulosin (0.4 mg daily) versus placebo or tamsulosin (0.4 mg daily) on the detection of any prostate cancers (Fig. 1). Patients using dutasteride in the Phase III monotherapy studies showed a significant decrease in risk (51\%) for detectable prostate cancer (MHRR: $0.49,95 \% \mathrm{Cl} 0.31-0.77$ ), as did patients in CombAT (MHRR: 0.63, 95\% Cl 0.45-0.87), and REDUCE (MHRR: $0.77,95 \% \mathrm{Cl} 0.70-0.85$ ). The test for heterogeneity illustrates moderate to high heterogeneity $\left(I^{2}=59.79\right)$, but was not statistically significant $(Q=4.97$, $p=0.08)$, and it was therefore reasonable to pool the results. The meta-analysis found a significant risk reduction (34\%) for detectable prostate cancers for patients using dutasteride, administered alone or as monotherapy with tamsulosin, compared to placebo or tamsulosin (MHRR: $0.66,95 \% \mathrm{CI}$ 0.52-0.85).

\section{For-cause prostate cancers}

For-cause cancers were defined as cancers detected during a biopsy required by the investigator as a result of an abnormal finding, such as elevated PSA or an abnormal digital rectal exam (DRE). Figure 2 describes the effect of dutasteride ( $0.5 \mathrm{mg}$ daily) or dutasteride ( $0.5 \mathrm{mg}$ daily) + tamsulosin $(0.4$ $\mathrm{mg}$ daily) versus placebo or tamsulosin ( $0.4 \mathrm{mg}$ daily) on prostate cancer risk reduction on for-cause prostate cancers. Since there were no scheduled biopsies in the Phase III BPH monotherapy or the CombAT studies, the for-cause cancer results were identical to any-prostate-cancer results for these studies as described above. The REDUCE trial did not show a statistically significant decrease in risk for patients using dutasteride for detectable prostate cancers (MHRR: $0.74,95 \% \mathrm{Cl} 0.53-1.02)$, although the risk reduction (26\%) was similar to risk reduction for any-prostate-cancer results $(23 \%)$. The test for heterogeneity illustrated low heterogeneity $\left(I^{2}=10.24\right)$ and was not statistically significant $(\mathrm{Q}=2.23$, $p=0.33$ ), and therefore was reasonable to pool results. The meta-analysis found a significant risk reduction (37\%) for detectable for-cause cancer in patients using dutasteride compared to placebo or tamsulosin (MHRR: $0.63,95 \% \mathrm{Cl}$ 0.52-0.78).

\section{Gleason 7-10 prostate cancers}

We describe the effect of dutasteride $(0.5 \mathrm{mg}$ daily) or dutasteride $(0.5 \mathrm{mg}$ daily $)+$ tamsulosin $(0.4 \mathrm{mg}$ daily) vs. placebo or tamsulosin ( $0.4 \mathrm{mg}$ daily) on the risk of detectable Gleason 7-10 prostate cancers (Fig. 3). As Gleason scoring was not prospectively collected in the BPH monotherapy studies, these studies were excluded for this endpoint. The REDUCE trial did not show a statistically significant increased risk for patients using dutasteride for detectable 
Monga et al.

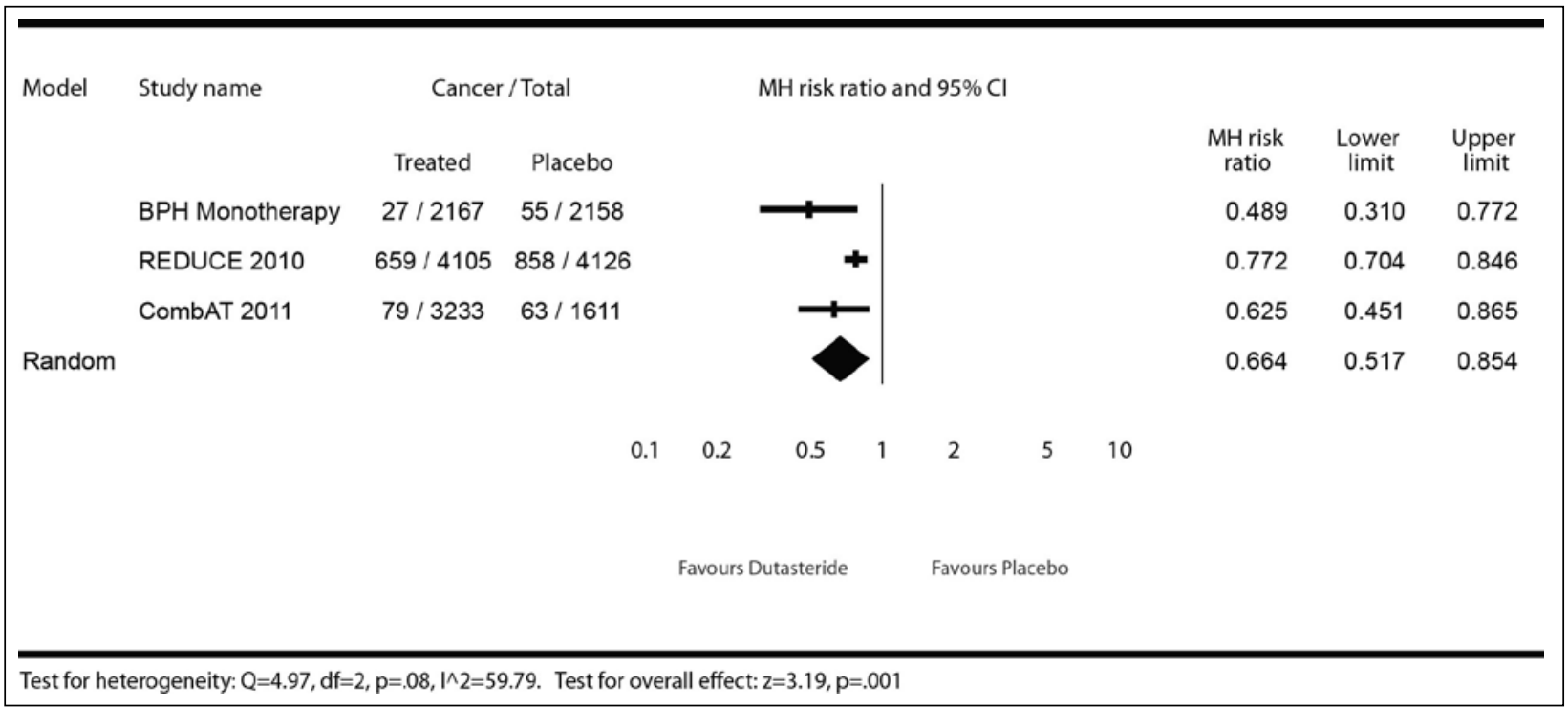

Fig. 1. Effect of dutasteride ( $0.5 \mathrm{mg}$ daily) or dutasteride $(0.5 \mathrm{mg}$ daily $)+$ tamsulosin ( $0.4 \mathrm{mg}$ daily) vs. placebo or tamsulosin ( $0.4 \mathrm{mg}$ daily) on risk of any prostate cancers.

Gleason 7-10 cancers (MHRR: 0.95, 95\% Cl 0.79-1.14), as did the CombAT trial (MHRR: 0.63, 95\% Cl 0.38-1.04). The test for heterogeneity illustrates moderate to high heterogeneity $\left(I^{2}=56.84\right)$, but was not statistically significant $(\mathrm{Q}=2.32, p=0.128)$, and was therefore reasonable to pool the results. The meta-analysis did not find a statistically significant increased risk for detectable Gleason 7-10 cancers for patients using dutasteride, either as monotherapy or in combination with tamsulosin, compared to placebo or tamsulosin monotherapy (MHRR: 0.83, 95\% Cl 0.56-1.21).

\section{Gleason 8-10 cancers}

On risk of detectable Gleason 8-10 prostate cancers, we describe the effect of dutasteride (0.5 mg daily) or dutasteride $(0.5 \mathrm{mg}$ daily) + tamsulosin (0.4 mg daily) versus placebo or tamsulosin (0.4 mg daily) (Fig. 4). Gleason scoring was not prospectively collected in the $\mathrm{BPH}$ monotherapy studies, and therefore, was excluded for this endpoint. The REDUCE trial showed no statistically significant increased risk for patients using dutasteride for detectable Gleason 8-10 cancers (MHRR: $1.53,95 \% \mathrm{Cl} 0.86-2.73$ ), as did

\begin{tabular}{|c|c|c|c|c|c|c|c|c|c|c|c|c|}
\hline \multirow[t]{5}{*}{ Model } & Study name & \multicolumn{2}{|c|}{ Cancer / Total } & & \multicolumn{8}{|c|}{$\mathrm{MH}$ risk ratio and $95 \% \mathrm{Cl}$} \\
\hline & & Dutasteride & Placebo & & & & & & & $\begin{array}{c}\text { MH risk } \\
\text { ratio }\end{array}$ & $\begin{array}{l}\text { Lower } \\
\text { limit }\end{array}$ & $\begin{array}{l}\text { Upper } \\
\text { limit }\end{array}$ \\
\hline & BPH Monotherapy & $27 / 2167$ & $55 / 2158$ & & & & & & & 0.489 & 0.310 & 0.772 \\
\hline & REDUCE 2010 & $63 / 4049$ & $86 / 4073$ & & & & & & & 0.737 & 0.534 & 1.017 \\
\hline & CombAT 2011 & $79 / 3233$ & $63 / 1611$ & & & & & & & 0.625 & 0.451 & 0.865 \\
\hline \multirow[t]{3}{*}{ Fixed } & & & & & & & & & & 0.634 & 0.517 & 0.778 \\
\hline & & & 0.1 & 0.2 & 0.5 & 1 & 2 & 5 & 10 & & & \\
\hline & & & & \multicolumn{3}{|c|}{ Favours Dutasteride } & \multicolumn{3}{|c|}{ Favours Placebo } & & & \\
\hline
\end{tabular}

Fig. 2. Effect of dutasteride ( $0.5 \mathrm{mg}$ daily) or dutasteride $(0.5 \mathrm{mg}$ daily $)+$ tamsulosin $(0.4 \mathrm{mg}$ daily) vs. placebo or tamsulosin ( $0.4 \mathrm{mg}$ daily) on prostate cancer risk of "for-cause" cancers. 


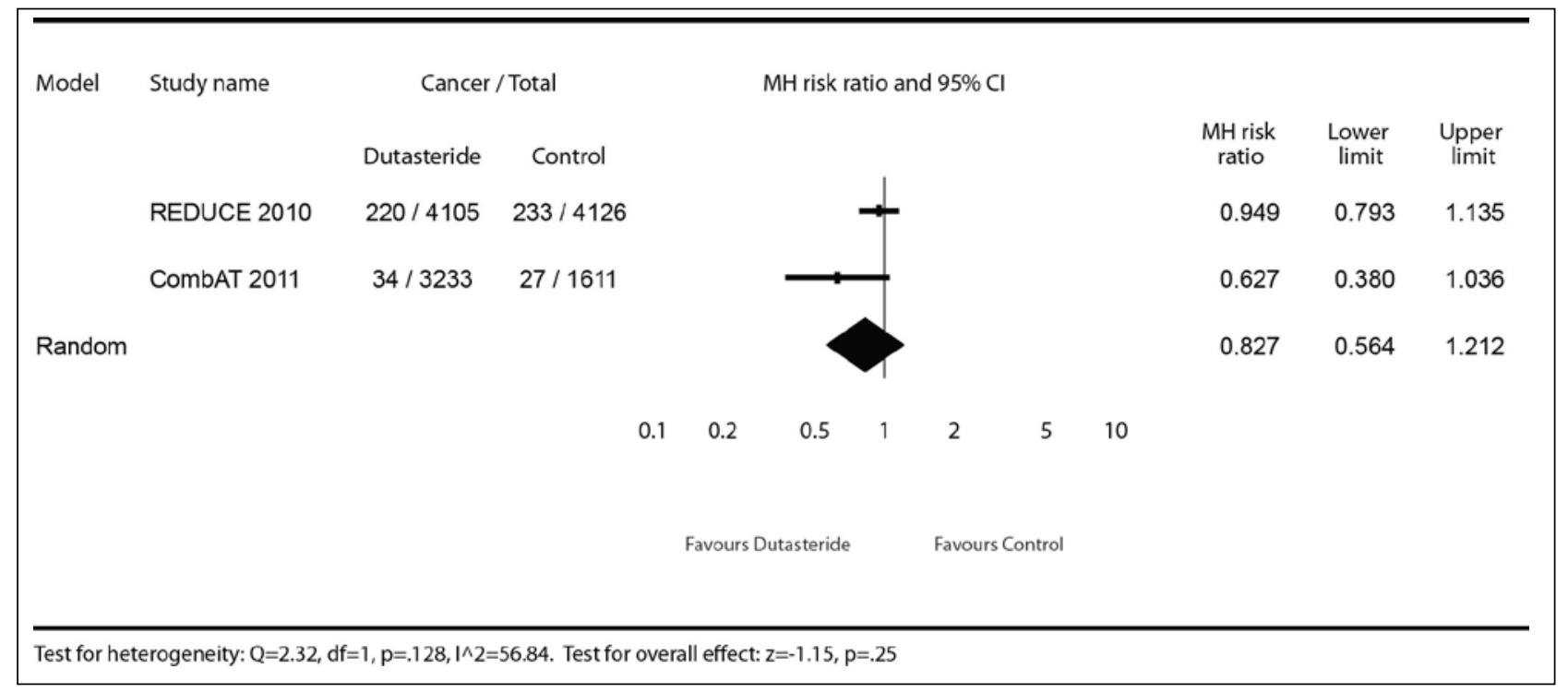

Fig. 3. Effect of dutasteride $(0.5 \mathrm{mg}$ daily) or dutasteride $(0.5 \mathrm{mg}$ daily $)+$ tamsulosin $(0.4 \mathrm{mg}$ daily) vs. placebo or tamsulosin (0.4 $\mathrm{mg}$ daily) on prostate cancer risk of Gleason grade 7-10 cancers.

CombAT (MHRR: $0.59,95 \% \mathrm{Cl} 0.26-1.31$ ). The test for heterogeneity illustrates high heterogeneity $\left(I^{2}=72.37\right)$, but was not statistically significant at the pre-specified alpha level of $p<0.05$ ( $\mathrm{Q}=3.62, p=0.06)$, and represented only dutasteride randomized controlled trials that measured this endpoint. It is understood that heterogeneity statistics may lack necessary power, however, it was felt that pooling the data (as was done for Gleason 7-10 cancers) provided additional scientific insight. There was no evidence of a significant increased risk for detectable Gleason 8-10 prostate cancers in the meta-analysis in subjects using dutasteride, administered alone or in combination with tamsulosin, compared to placebo or tamsulosin monotherapy (MHRR: 0.99, $95 \% \mathrm{Cl} 0.39-2.53)$.

\section{Discussion}

This meta-analyses pooled data from over 9500 men and represented an exposure of 25900 patient-years. In the dutasteride arms, the data demonstrated a statistically significant reduction in the overall risk of detectable prostate cancer by $34 \%$ to $37 \%$ (any-prostate-cancer and for-cause cancers using classical Gleason scores) in men with BPH or in men at an increased risk of prostate cancer. From the meta-analysis of CombAT and REDUCE, there was no significantly increased risk of detectable Gleason 7-10 or Gleason 8-10 prostate cancers in men taking dutasteride, either alone or in combination with tamsulosin, over placebo or tamsulosin monotherapy.

These data are consistent with published results for the treatment of $\mathrm{BPH}$ in symptomatic men with enlarged prostates. The BPH monotherapy studies showed a significantly reduced risk of detectable prostate cancer of $43 \%$ at 24 months and $51 \%$ at 27 months in men taking dutasteride over placebo. ${ }^{8}$ High-grade tumours were not reported in the $\mathrm{BPH}$ monotherapy trials. The CombAT study showed a $40 \%$ relative risk reduction of detectable prostate cancer compared to tamsulosin monotherapy over 4 years (combination therapy vs. tamsulosin: $43 \%, p=0.006$; dutasteride monotherapy vs. tamsulosin: $37 \%, p=0.021) .{ }^{9}$ This reduction in prostate cancer with dutasteride, alone or in combination with tamsulosin, was observed across all Gleason scores. ${ }^{9}$ Over the 4 year study, there were numerically fewer Gleason score 7-10 tumours (combination: $n=12$; dutasteride: $n=22$; tamsulosin: $\mathrm{n}=27$ ) and Gleason score 8-10 tumours (combination: $n=5$; dutasteride: $n=8$; tamsulosin: $n=11$ ) in the dutasteride groups combined, compared with the tamsulosin group. ${ }^{9}$ The reduction in risk of detectable prostate cancers is further confirmed in the recently published REduction by Dutasteride of clinical progression Events in Expectant Management (REDEEM) trial, in which numerically fewer cases of Gleason 8 tumours in the dutasteride arm $(n=2)$ compared to placebo $(n=3)$ over 3 years were observed, in men who already had low-risk, low-grade cancers (T1c-T2a, Gleason score $<6$ and no Gleason pattern score $\geq 4)$. ${ }^{13} \mathrm{No}$ Gleason 9 or 10 tumours were detected..$^{13}$

Concern has been raised about the increased incidence of Gleason 8-10 high-grade tumours in the REDUCE and PCPT studies. ${ }^{12}$ When modified Gleason scores were used, an increased incidence of Gleason 8-10 cancers with finasteride $(1.8 \%)$ and dutasteride $(1.0 \%)$ over placebo $(1.1 \%$, $0.5 \%$, respectively) was reported. ${ }^{12}$ Furthermore, no increase was seen in the detection of Gleason 7-10 cancers, and a lower incidence was observed in low-grade cancers 


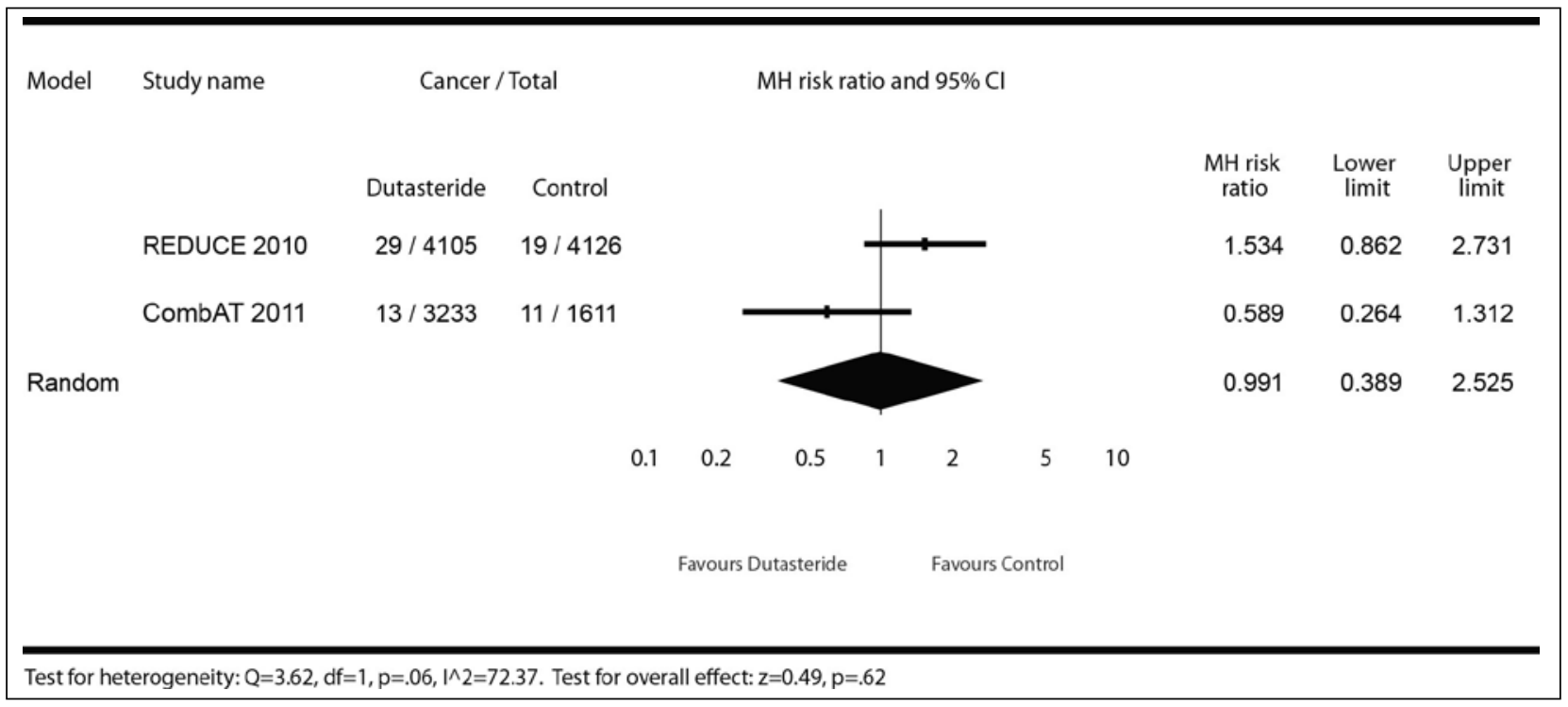

Fig. 4. Effect of dutasteride $(0.5 \mathrm{mg}$ daily) or dutasteride $(0.5 \mathrm{mg}$ daily $)+$ tamsulosin $(0.4 \mathrm{mg}$ daily) vs. placebo or tamsulosin (0.4 $\mathrm{mg}$ daily) on prostate cancer risk of Gleason grade 8-10 cancers.

(Gleason $\leq 6) .{ }^{12}$ It is unclear whether the increased incidence of high-grade tumours was due to histopathologic artifacts such as selective reduction in overall prostate volume or low grade prostate cancer lesion caused by 5ARIs, rather than representing actual biologic activity of the tumour. However, the possibility that 5ARIs may increase the growth or the development of high grade prostate cancer cannot be ruled out. This has led to increasing concern amongst physicians and patients about the safety of 5ARIs in the management of $\mathrm{BPH}$.

There are differences among the baseline patient characteristics in these clinical studies. The patient population enrolled in the BPH studies, defined by moderate to severe symptoms, prostate volume $\geq 30 \mathrm{cc}, \mathrm{PSA} \geq 1.5 \mathrm{ng} / \mathrm{mL}$ and IPSS $\geq 12$, is the more clinically relevant patient population that is prescribed a 5-ARI to manage $\mathrm{BPH}$ symptoms, according to national guidelines in Canada, the European Union and the U.S. In contrast, the REDUCE study included a population that was already at a higher risk of developing prostate cancer, as defined by the increased PSA values $(>2.5 \mathrm{ng} / \mathrm{mL})$ and higher prostate volumes $(\leq 80 \mathrm{cc})$. Despite these differences, in this meta-analysis, dutasteride showed a reduction in risk of detectable prostate cancer (any-prostatecancers and for-cause), and there was no significant increase in the detection of high-grade tumours between the CombAT and REDUCE populations (groups which ranged in baseline prostate volumes and PSA values) (Table 1).

It has been well-established that 5-ARIs reduce serum PSA levels. Since the PSA test is commonly used to screen for prostate cancer, there is a concern that 5-ARIs could lead to a false negative PSA test, causing physicians to miss detect- able prostate cancer. However, dutasteride has been shown to maintain the utility of the PSA measurement in detecting prostate cancer. ${ }^{17,18}$ The CombAT and REDUCE studies suggested that there was an improved detection of prostate cancer in PSA-driven biopsies, that is, when a rise in PSA values from the nadir, following initiation of dutasteride therapy, resulted in a biopsy. ${ }^{9,17}$ Kaplan and colleagues recently demonstrated that 5-ARIs improved the detection of highgrade cancers using the rate of change from the PSA nadir as a marker. ${ }^{19}$ For the general practitioner who manages $\mathrm{BPH}$ patients and typically worries about missing prostate cancer, ${ }^{20}$ our study provides additional reassurance that a PSA rise from a new baseline established 3 to 6 months after starting dutasteride therapy will increase the likelihood of detecting prostate cancer. Furthermore, while inter-observer variability and the general upgrading of tumours using the modified Gleason scoring has been well-documented, ${ }^{21}$ the predictive value of PSA changes from nadir is maintained. ${ }^{22}$ There is also a good correlation between tumour grade and stage, and serum PSA values, which may further characterize the difference between low- and high-grade malignancy of prostate carcinoma. ${ }^{22-24}$

The findings in the present study are further supported by the recent Consensus Statement from the Canadian Urological Association..$^{25}$ The statement critically analyzed the available data on the benefit-risk of 5-ARIs. The CUA panel stated that 5-ARIs can be safely used to treat BPH in men with an enlarged prostate; however, the panel reiterated the need for a robust conversation between the physician and the patient on the risks and benefit of treatment. Regular monitoring using PSA was further reinforced. 


\section{Limitations}

There were several limitations in this meta-analysis. Gleason scoring was not prospectively collected in the BPH monotherapy (ARIA3001, ARIA3002, ARIB3003) studies and this may have affected our results. Gleason scores were also not included in the analyses of Gleason 7-10 and Gleason 8-10 cancers. In CombAT and REDUCE, only for-cause biopsies were conducted, whereas REDUCE called for both protocoldefined and for-cause biopsies. Additionally, the Gleason scoring methodology was not consistent between the CombAT and REDUCE trials. There was no central pathology review in the dutasteride monotherapy and CombAT studies, resulting in lack of standardization and different interpretations and grading for the primary endpoint of interest in these analyses. The meta-analyses did not adjust for number of biopsies in the different trials. Finally, the analyses pooled trial results that had fundamentally different designs, population and methodology to evaluate prostate cancer status, and statistical tests for three of the four outcomes analyzed presented with moderate to high heterogeneity.

\section{Conclusions}

This is the first study to evaluate the impact of dutasteride for prostate cancer detection based on a meta-analysis of all GSK-sponsored trials. While the analysis had several limitations, the results showed that dutasteride reduced the risk of detectable prostate cancer, including low-grade prostate cancers, which are less likely to lead to death. Additionally, in our analysis, there was no increased risk of detectable high-grade prostate tumours, defined by Gleason $\geq 7$ scores, as shown in CombAT and REDUCE. These data support the use of dutasteride in the typical clinical management of $\mathrm{BPH}$, with patients appropriately monitored by their physicians.

Competing interests: All authors of this manuscript are employees of GlaxoSmithKline.

This paper has been peer-reviewed.

\section{References}

1. Berry SJ, Coffey DS, Walsh PC, et al. The Development of Human Benign Prostatic Hyperplasia With Age. J Urol 1984;132:474-9.

2. Garcia M, Jemal A, Ward EM, et al. Global Cancer Facts \& Figures 2007. 2007. Atlanta, GA. Available at http://www.cancer.org/acs/groups/content/@nho/documents/document/globalfactsandfigures2007rev2p.pdf. Accessed March 7, 2013.

3. Rawson N, Saad F. The Aging Male Population and Medical Care for Benign Prostatic Hyperplasia in Canada. Can Urol Assoc J 2010;4:123-7. http://dx.doi.org/10.5489/cuaj.09092
4. Wei JT, Calhoun E, Jacobsen SJ. Urologic Diseases in America Project: Benign Prostatic Hyperplasia. J Urol 2005;173:1256-61. http://dx.doi.org/10.1097/01.ju.0000155709.37840.fe

5. Roehrborn CG, Boyle P, Nickel JC, et al. Efficacy and Safety of a Dual Inhibitor of 5-Alpha-Reductase Types 1 and 2 (Dutasteride) in Men With Benign Prostatic Hyperplasia. Urology 2002;60:434-41. http:// dx.doi.org/10.1016/S0090-4295(02)01905-2

6. Clark RV, Hermann DJ, Cunningham GR, et al. Marked Suppression of Dihydrotestosterone in Men With Benign Prostatic Hyperplasia by Dutasteride, a Dual 5alpha-Reductase Inhibitor. J Clin Endocrinol Metab 2004;89:2179-84. http://dx.doi.org/10.1210/ic.2003-030330

7. Gormley GJ, Stoner E, Bruskewitz RC, et al. The Effect of Finasteride in Men With Benign Prostatic Hyperplasia. N EnglJ Med 1992;327:1 185-91. http://dx.doi.org/10.1056/NEJM199210223271701

8. Andriole GL, Roehrborn C, Schulman C, et al. Effect of Dutasteride on the Detection of Prostate Cancer in Men With Benign Prostatic Hyperplasia. Urology 2004;64:537-41. hittp://dx.doi.org/10.1016/i. urology.2004.04.084

9. Roehrborn CG, Andriole GL, Wilson TH, et al. Effect of Dutasteride on Prostate Biopsy Rates and the Diagnosis of Prostate Cancer in Men With Lower Urinary Tract Symptoms and Enlarged Prostates in the Combination of Avodart and Tamsulosin Trial. Eur Urol 2011;59:244-9. http://dx.doi.org/10.1016/i. eururo.2010.10.040

10. Thompson IM, Goodman PJ, Tangen CM, et al. The Influence of Finasteride on the Development of Prostate Cancer. N Engl J Med 2003;349:215-24. http://dx.doi.org/10.1056/NEJMoa030660

11. Andriole GL, Bostwick DG, Brawley OW, et al. Effect of Dutasteride on the Risk of Prostate Cancer. N Engl J Med 2010;362:1 192-202. http://dx.doi.org/10.1056/NEJMoa0908127

12. Theoret MR, Ning YM, Zhang JJ, et al. The Risks and Benefits of 5a-Reductase Inhibitors for Prostate-Cancer Prevention. N Engl J Med 2011;365:97-9. http://dx.doi.org/10.1056/NEJMpl 106783

13. Fleshner NE, Lucia MS, Egerdie B, et al. Dutasteride in Localised Prostate Cancer Management: the REDEEM Randomised, Double-Blind, Placebo-Controlled Trial. Lancet2012;379:1103-11. http://dx.doi. org/10.1016/S0140-6736(11)61619-X

14. Lau J, loannidis JPA, Schmid CH. Quantitative Synthesis in Systematic Reviews. Ann Intern Med 1997; 127:820-6.

15. Zintzaras E, loannidis JPA. Heterogeneity Testing in Meta-Analysis of Genome Searches. Genet Epidemiol 2005;28:123-37. http://dx.doi.org/10.1002/gepi.20048

16. Borenstein M, Hedges L, Higgins J, et al. Comprehensive Meta-analysis, Version 2, Biostat, Englewood NJ; 2005.

17. Andriole GL, Bostwick D, Brawley OW, et al. The Effect of Dutasteride on the Usefulness of Prostate Specific Antigen for the Diagnosis of High Grade and Clinically Relevant Prostate Cancer in Men With a Previous Negative Biopsy: Results From the REDUCE Study. J Urol 2011;185:126-31. http://dx.doi. org/10.1016/i.juro.2010.09.011

18. Marberger M, Freedland SJ, Andriole GA, et al. Usefulness of prostate-specific antigen (PSA) rise as a marker of prostate cancer in men treated with dutasteride: lesson from the REDUCE study. BJU Int 2012;109:1162-9. http://dx.doi.org/10.1111/j.1464-410X.2011.10373.x

19. Kaplan $S A$, Lee RK, Chung DE, et al. Prostate biopsy in response to a change in nadir prostate specific antigen of $0.4 \mathrm{ng} / \mathrm{mL}$ after treatment with $5 \alpha$-reductase inhibitors markedly enhances the detection rate of prostate cancer. J Urol 2012;188:757-61. http://dx.doi.org/10.1016/i.juro.2012.04.111

20. Yafi FA, Aprikian AG, Tanguay $S$, et al. Are Men on 5alpha-Reductase Inhibitors Appropriately Referred to Urology? A Survey of Primary Care Physicians. BJU Int 2011;108:1269-73. http://dx.doi. org/10.1111/i.1464-410X.2010.09984.x

21. Epstein, Jl, Allsbrook, Amin MB, et al. The 2005 International Society of Urological Pathology (ISUP), Consensus Conference on Gleason Grading of Prostatic Carcinoma. Am I Surg Pathol 2005;29:1228-42.

22. Delahunt B, Lamb DS, Srigley JR, et al. Gleason Scoring: a Comparison of Classical and Modified (International Society of Urological Pathology) Criteria Using Nadir PSA As a Clinical End Point. Pathology 2010;42:339-43. http://dx.doi.org/10.3109/00313021003787924

23. Billis A, Guimaraes MS, Freitas LL, et al. The Impact of the 2005 International Society of Urological Pathology Consensus Conference on Standard Gleason Grading of Prostatic Carcinoma in Needle Biopsies. J Urol 2008;180:548-52. http://dx.doi.org/10.1016/i.juro.2008.04.018

24. Helpap B, Egevad L. Modified Gleason Grading. An Updated Review. Histol Histopathol 2009;24:661-6.

25. Klotz L, Chetner M, Chin J, et al. Canadian Consensus Conference: The FDA decision on the use of 5ARls. Can Urol Assoc J 2012;6:83-8.

Correspondence: Dr. Zhen Su, GlaxoSmithKline, Inc., 7333 Mississauga Rd, Mississauga, ON L5N 6L4; fax: 905-819-3099; zhen.x.su@gsk.com 